\title{
Mapping Literature Through Quantitative Instruments. The Case of Current Romanian Literary Studies
}

\author{
DAIANA GÂRDAN \\ EMANUEL MODOC
}

\begin{abstract}
Following a two-pronged line of argumentation, our article seeks to analyze and evaluate the current state of quantitative approaches applied to Romanian literature within the context and framework of one of the most prominent emergent fields of literary studies: quantitative formalism. Thus, on the one hand, the paper will attempt to present the most well-known lexicographic instruments currently used in quantitative studies in Romania (The Chronological Dictionary of the Romanian Novel from its Origins to 1989, The Chronological Dictionary of Translated Novels in Romania from its Origins to 1989, and The Bibliography of the Relations between Romanian Literature and Foreign Literatures in Periodicals 1919-1944), and, on the other, to employ the emerging methods that make use of these instruments, alongside their inherent limitations and the pragmatic issues that concern them) as a starting point for a debate on the current state of theoretical and critical approaches to the study of literature in the Romanian academic field. A selective and detailed application of the quantitative methodologies in question, as they are theorized by scholars such as Franco Moretti ("distant reading”) or Matthew L. Jockers ("macroanalysis") will be another focal point of our paper, as it will seek to further illustrate the manner in which a meta-reflection on the approach itself can encourage the further development of quantitative methods in the study of Romanian literature.
\end{abstract}

Keywords: Romanian literature; World literature; distant reading; quantitative studies; macroanalysis

Our inquiry into the development of quantitative literary studies in the Romanian cultural and academic fields stems from a rather unambiguous paradox regarding how local academics approach emerging theoretical methods: not nearly a decade after the first timid advancements into World Literature Studies and contemporary quantitative and digital methods have started to be a subject of crucial debates; "state-of-the-art" studies investigating how these methods were localized in the Romanian academic environment (Patraș et al. 2019: 207-222) have already been published. What we set out to accomplish 
in the current paper is to retrace the steps taken in recent years in order to better understand the current state of literary studies in a non-centric national culture such as Romania. The wider literary and cultural context surrounding our approach to Romanian literature through the methodologies that we are about to illustrate is linked to what newer Marxist social theorists coined "the theory of combined and uneven development" (WReC 2015). While in cultures such as the United States, digital and quantitative approaches have made their debut as early as the second half of the $20^{\text {th }}$ century, the relatively enthusiastic reception of these methods within the Romanian academic world of the last decade may call into question the issue of academic self-colonization. However, while the emergence of World Literature studies may be seen, in the West, as attempts to transform the humanities into a neoliberal haven that will ultimately threaten the very core of the field itself, we will concede that, as far as Romanian culture is concerned, the expanding interest in quantitative/digital formalism may yet prove a revival of autochthonous literary studies. The most recent explorations in this field and the shift from traditional hermeneutics to more interdisciplinary approaches strive to confirm or to refute the validity of a series of theoretical and critical assumptions that have become commonplace in the Romanian literary historiography. These approaches did not, however, enjoy an undisturbed trajectory, nor were they met with the kindest of feedbacks, as was the case with Romanian Literature as World Literature, the recent volume edited by Mircea Martin, Christian Moraru and Andrei Terian (Martin, Moraru, Terian 2018), which was the object of unreserved admiration among foreign academics, but has been met with hostilities in the Romanian literary space (Burța-Cernat 2018).

By much the same token, among the limitations and difficulties faced by most Romanian scholars engaging with distant reading, we find the lack of digitized corpora and the - challenging, often problematic and deeply bureaucratized - process of accessing library archives in order to create specialized digital collections for research purposes also worth mentioning. The emerging research projects and academic studies or volumes that aim to implement these methods in the local academic field have to reconsider doubling back in order to create exhaustive archives and corpora, which will ultimately be used to reassess the conclusions/verdicts/results obtained using present resources.

Another decisive factor that should be taken into consideration when discussing these new methodologies approached with old tools is the very belatedness that caused most of the major literary dictionaries in Romania to be edited only in the last seven decades. The very "tradition" of constructing 
GÂRDAN, MODOC

various dictionaries in the Romanian cultural space has more or less defined the specific way in which contemporary quantitative approaches are conducted. In the absence of digitized literary corpora and specialized databases for quantitative analyses of literary phenomena, most of the distant reading approaches of Romanian novels or modern(ist) cultural production have been attempted using lexicographical instruments such as dictionaries and bibliographies. This process, in turn, generated a fair share of additional efforts on the part of the scholars involved, especially in the case of individual undertakings. Because detailed historical accounts on the development of quantitative researches in the Romanian cultural space have already been made (Bâlici 2018: 54-71; Terian 2019: 55-71), we will not go into the factors that have determined the method's revival in Romania. We will instead focus on how the aforementioned dictionaries, along with their inherent technical limitations, shaped the development of contemporary quantitative approaches. It should be noted from the very beginning that these lexicographical instruments were initially conceived as tools for traditional literary and historiographical approaches, as a go-to analog reference system for various close-reading analyses. A central consequence of this is that, as far as distant readings are concerned, the metadata provided by these dictionaries and bibliographies lack any sort of structural and thematic coherence. Therefore, a great deal of preliminary interpretation of the metadata itself is required prior to the interpretation of the actual data. Before we begin demonstrating the practical uses of these instruments, a short description of each tool is appropriate.

The Chronological Dictionary of the Romanian Novel from its Origins to 1989 (from hereon DCRR) is an exhaustive database that indexes all novels ever published - either as book or as feuilleton - in the Romanian literary space. This includes both serialized novels (finished, as well as unfinished) and the ones edited by publishing houses. The primary metadata, and the only ones coherent throughout the dictionary, consist of the author's full name, the title of the novel, the year of publication, the page count, and the information regarding the publishing house or - in the case of periodicals - the bibliographical references. Using a quantitative approach on these sets of data alone can provide details regarding the frequency of an author's publication, the prevalence of one publishing house over the other or the authors' overall prestige in the public sphere. The dictionary also provides short synopses of the novels containing, to varying degrees of accuracy and intricacy, information regarding their subgenre, the time and space wherein the narratives unfold, details about the main characters or the ideological and cultural context 
surrounding their publication. The main challenges of quantitative approaches are, thus, rooted in the heterogeneity of this particular segment of the dictionary's (meta)database. Being a collective endeavor, it lacks a cohesive "style guide" for the elaboration of the descriptions. Genre-specific details are heavily dependent on the subjectivity of the researcher that worked on each batch of novels. The rural novel, for instance. This subgenre has an extremely rich critical and historiographical legacy in the Romanian cultural space, as it is often regarded as both the most quantitatively dominant novelistic form and the most dominant trait of Romanian literature. Yet this historiographical cliché emerged in the absence of any comprehensive study on the Romanian novel (Borza 2019: 21-40). As a direct consequence, the dictionary uses the phrase "rural novel" quite loosely, affecting the overall results of a quantitative approach. Geocritical quantitative approaches are also burdened by the data's inaccuracy, as spatial references in the novel are only partially covered. The only clear delimitation drawn by the data concerns the divide between urban and rural spaces; additionally, transitional, interstitial spaces (the peripheries, the slums, the ghettos) are also supplied.

The Chronological Dictionary of Translated Novels in Romania from its Origins to 1989 (DCRT) makes an inventory of all the novels translated in the Romanian cultural space by using secondary and tertiary instruments (bibliographies, critical and periodical references). The main data granted by this tool provides the authors' names, the titles and countries of origin, alongside the years of translation. While no additional descriptions are given, this dictionary is, nevertheless, extremely useful for analyzing foreign cultural imports, through which the researcher can extrapolate national intercultural politics throughout different historical or ideological contexts (Baghiu 2019a: 487-503).

Last but not least, The Bibliography of the Relations between Romanian Literature and Foreign Literatures in Periodicals 1919-1944 is probably the most comprehensive reference database of the three. The ten volumes that make up the Bibliography consist of over 80,000 articles from over 700 Romanian periodicals, with comprehensive classifications based on thematic and national criteria. Published between 1997-2009, it offers a full account of the reception of modernist factions in Romanian culture and of a period when magazine culture was at its peak. The sheer potential of this instrument has not yet been exploited, although some preliminary attempts have been made (Modoc 2018: 45-61). What the Bibliography first and foremost offers is the ability to circumvent the need to digitize Romanian inter-war periodicals in their entirety, an endeavor that is expected to be still out of reach for years to come. 
GÂRDAN, MODOC

With all the necessary information at hand, this tool can be used extensively for a comparative analysis of literary influence and popular trends within modernist literature. The only major downside concerning this lexicographical project is that it understandably lacks an equally comprehensive counterpart covering the reception of Romanian literature abroad. Another shortcoming is that the cited articles are only concerned with literary topics, rendering interdisciplinary investigations that could offer more refined results troubling.

In spite of the limitations presented, DCRR and DCRT have managed to generate some pioneering works in the field of quantitative studies in Romania, with relevant results that question a series of critical clichés with respect to the nature of the Romanian novel or the position occupied by Romanian culture in the international cultural field. One of the first contemporary quantitative approaches departing from DCRT belongs to Ștefan Baghiu (Baghiu 2016: 5-18), who offers a comprehensive overview of novelistic translation during the period of socialist realism and succeeds incompletely refuting the critical consensus that the period was under the cultural domination of the Soviet Union. In subsequent studies, Baghiu extends his investigations to the whole of Communist-era Romanian culture (Baghiu 2019a: 487-503, Baghiu 2019b: 83-100). DCRR has, in turn, stimulated a number of World Literature approaches to the Romanian novel. Andrei Terian's results are particularly relevant (Terian 2019: 55-71), as he puts forward a four-pronged delimitation of the evolution of the Romanian novel, taking into account aspects such as the autochthonous production of the novel in comparison to the number of translations during the same period, the links between novel production and cultural or ideological politics of a given period, the particularities of the growth and transformation of this literary corpus and the dynamics of literary markets. More specifically, genre or gender-specific approaches using "secondary" metadata provided by DCRR were dedicated to particular time periods such as the first half of the $20^{\text {th }}$ century (Gârdan 2018a: 5-10, Gârdan 2018b: 109-124).

The quantitative investigations resulted from consulting the two dictionaries are, however, highly experimental in nature, merely exploring the possibilities of implementing this method on a national scale. For a short demonstration of these methods, we provide the following example that concerns the evolution of the Romanian romance novel between 1900 and 1940. A visual representation of this evolution yielded the following graph: 
Mapping Literature Through Quantitative Instruments

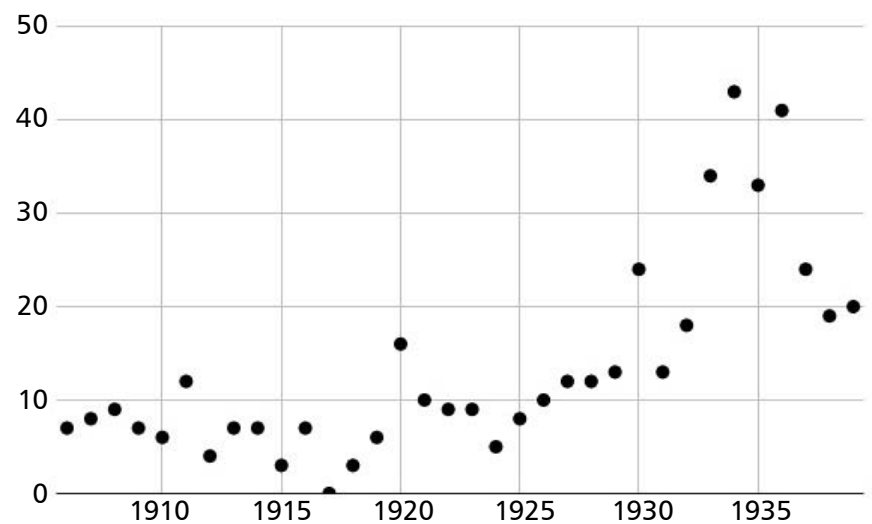

Figure 1. The evolution of romance novels between 1900-1940 in Romania

This figure represents the basic quantitative distribution of the number of romance novels published yearly in Romania. Before selecting the information from DCRR, we had to first establish what a romance novel is. The general condition of our selection was either that the plot focused on the love story between two protagonists or that the narrative possessed an erotic undertone (Ramsdell 1999: 3-5). However, in order to better understand the quantitative representation above, we require a baseline against which to compare it.

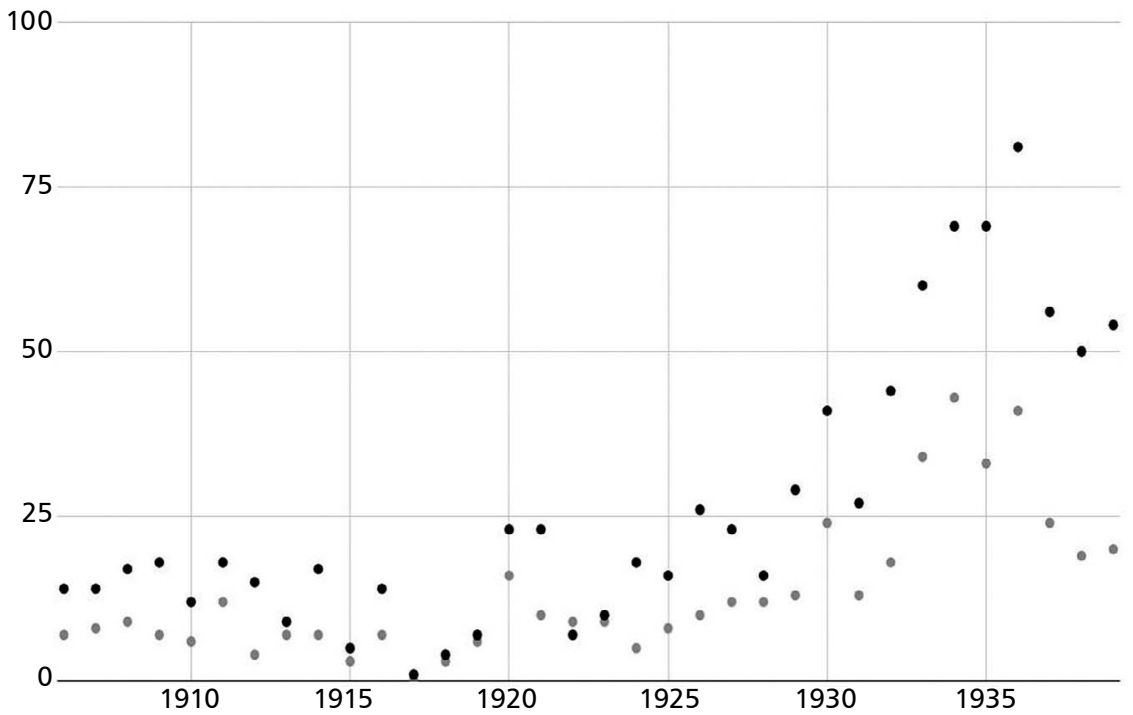

Figure 2. The number of romance novels in relation to the total novelistic production (1900-1940) 
GÂRDAN, MODOC

This second graph emphasizes two key aspects regarding the Romanian novel of the period: 1 . the role of the romance plot in the modernization of the Romanian novel and 2. the place of the romance novel in the context of the total novelistic production (Figure 2). In regard to the first point, the fact that the number of published romance novels closely follows the overall novel production of the period shows that the Romanian romance novel mirrors the evolutionary trajectory of the modern Romanian novel almost perfectly, which helps demonstrate that the erotic plot was essential to the advancement of the novelistic form. Correspondingly, the overall percentage of romance novels in relation to the whole shows that this subgenre was among the most dominant in the period, with a distribution of $30 \%$

What we attempted to illustrate in the analysis above is merely a part of a much more substantial research project that poses many challenges. Defining the subgenres is a problematic process on its own, as is the case with any genrecentric approach. However, the relevance of such results is far from negligible, since panoramic approaches to literature are generally closer to the reality of literary production than investigations which limit themselves to specific canonical works. In the context of World Literature, the "journey" of a specific national literature is, thus, far more relevant than the central positions of aesthetically valuable literary works (i.e. the canon), as it takes into account a series of cultural chain reactions ensuing a sustained dialogue between the foreign (be it central of peripheral) and the local through translation and cultural import.

Moving on to other types of quantitative approaches, the aforementioned Bibliography of international relations between Romanian literature and foreign literatures provides a fertile ground for the elaboration of literal networks of modernist cultural production. Drawing on quantitative data and on what Pierre Bourdieu coined "the field of cultural production" (Bourdieu 1996), our next demonstration aims to exhibit the network of modernism in the Romanian cultural field during the interwar period, as it can be traced departing from the reception of modern artistic currents in the national periodicals of the time. The starting point of this brief demonstration builds upon the assumption that the Romanian modernist press was the main venue for the dissemination of artistic modernism in Romania, while at the same time doubling as platform of socio-political critique. While morphologic similarities between Western and Eastern artistic trends did, as Steven Mansbach argued, point towards important transnational connections across the continent (Mansbach 1999: 3-4), modernism's reception in Romania can reveal other, more interesting, phenomena. One of them concerns the frequency of articles 
related to modernist movements published both in the capital of Bucharest and, to a surprisingly large extent, in the provinces as well. Another point of interest concerns the mechanisms by which modern artistic trends, albeit enjoying an in-depth reception in the Romanian cultural press, were met with strange reluctance in terms of emulation and assimilation. The data employed in the following analysis, which will bring together network analyses in the form of computational processing, was mind from the Bibliography following digitization, since in its analog form, any exploratory data analysis would have been painstakingly difficult to obtain. The number of authors that could be extrapolated from the articles surveyed was of particular interest to us. This means that, while the background of these mentions has been ignored, we aimed at quantifying how much debate an author or another sparked in the Romanian periodical field.

This "distant reading” (Moretti 2013) can offer visual renditions of an entire "literary economy" (Jockers 2013: 28), while also revealing significant details otherwise unobtainable through close-reading. While data visualization cannot substitute actual interpretation, it can be hardly disputed that such approaches add to a rich hermeneutical and metadiscursive tradition by offering factual evidence of previous interpretations that based more on intuition than empirical proof. Far from proposing a "hegemony of numbers" (English 2010: 12), we argue that the use of network abstractions in order to visualize patterns could serve as arguments towards an alternative approach to literary sociology. Such resulting networks could provide the necessary data needed for a relational approach to the sociology of literature. Mustafa Emirbayer's manifesto for a relational sociology (Emirbayer 1997: 281-317) is the starting point of our attempt to use visual abstractions of networks in order to analyze interliterary relations among the actors of modernist cultural production. Emirbayer makes a very strong case for a shift from an inter-actional model, which refers to models of interaction produced between independent entities, towards a trans-actional model, according to which any and all transactions between individuals are not possible by isolating the specific relation between the individuals.

A short description of the methodology behind these visual abstracts is required: a network, in our use of the concept, represents any formal relation between multiple nodes, as it is visually represented through the edges that unite them. Interpreting the networks obtained through this process is, however, not without its caveats. As Dennis Tenen accurately pointed out, "despite the apparent quantification, network analysis is more of an art than a science" (Tenen 2017: 260). In order to cluster the otherwise amorphous data 
GÂRDAN, MODOC

mass, we have employed Gephi, a software that helps produce a series of layouts that render, in the form of a network, the physical properties of what we intend to illustrate: a "slice" of the Romanian literary field. The software's rendition of the data, however, is quite equivocal: albeit adhering to predetermined layouts, the spatial placement of one author or one magazine within the given network is never quite the same. This does not mean, however, that the "geography" of the networks shown below is not coherent. The center-periphery allocation in the network is conserved throughout, which means that the main nodes (in this case, the authors investigated) will always maintain their general position within the network.

Even though our approach required an exhaustive quantitative analysis, the networks resulted through this process demand additional interpretation. Nonetheless, the network visualizations obtained provide a starting point for the analysis of different intercultural phenomena. For the purpose of our first demonstration, our choice fell the critical reception of the three major figures of the historical avant-garde: F.T. Marinetti, André Breton, and Tristan Tzara. In order to graphically represent the reception of the three artists in the Romanian literary space, we had to first process the data through clustering.

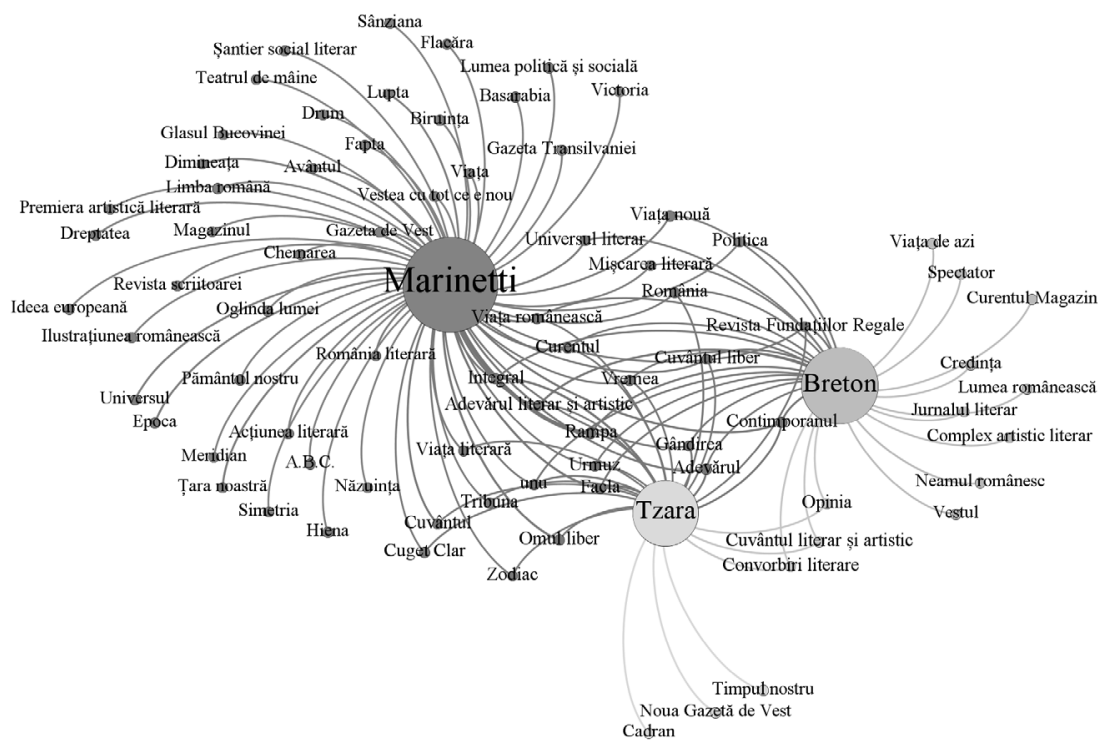

Figure 3. The network of mentions of three avant-garde artists in the Romanian literary field (1919-1944) 
In the case of the three main artists of the historical avant-garde, it can be clearly seen that, while there are a number of Romanian cultural magazines that share an interest in all three of them, each artist manages to gain a more or less "privileged" position in the field as a whole. Marinetti, for instance, is by far the most popular of the three, garnering an impressive number of unique magazines "devoted" to his reception. Beyond this succinct exposition, however, there is a more interesting question that needs to be addressed, and this requires a great deal of local contextualization: of all the artistic movements of this period, futurism stands out the most through the sheer quantity of articles (relative to the total amount) published on the topic of modernist currents. Apart from the quantitative aspect, the fact that there never was a true futurist movement in Romania, at least not in the sense of a self-conscious futurist group, with dedicated magazines, manifestos and activities (Modoc 2018: 46). In other words, how is it that the only avant-garde movement that had no real materialization in Romanian literature exhibits this kind of impact on and coverage in local periodicals? To further see the depth and breadth of the impact both of Marinetti and of futurism on the Romanian periodical field, we have extended our inquiry beyond the avant-garde. We have also added a scaling parameter to the edges. In other words, the "thicker" the edge between two nodes, the more articles are written in one magazine about one particular author.

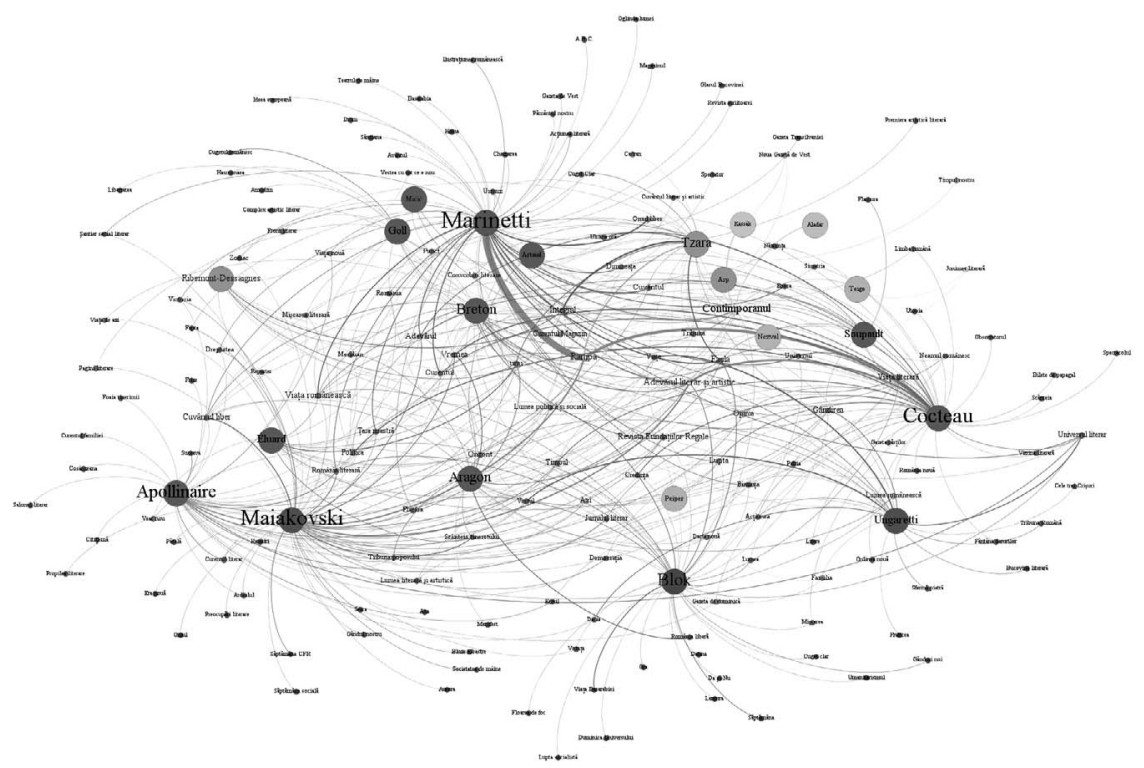

Figure 4. The network of mentions of 21 modernist authors in the Romanian literary field (1919-1944) 
GÂRDAN, MODOC

As we indicated above, the spatial stability of the networks processed through Gephi is arbitrary and non-deterministic, which means that the only reliable spatial distribution is based on center-periphery relations. This, in turn, means that the main "central" nodes of our network will not consist of authors, but rather of the magazines that mention more authors. Therefore, magazines such as Rampa (The Platform) or Adevărul (The Truth), which are the Romanian newspapers with the highest circulation in the country, will also be considered the central venues for modernism in the periodical field, while avant-garde magazines such as Contimporanul (The Contemporary), the main platform for the Romanian historical avant-garde, will be placed in the periphery of the network (Figure 4). But the resulting network compels us to make a series of inferences that are not supported by original assumptions that are now considered commonplace in our national literary historiography. One can note, beyond the influence of futurism in the cultural field outside the avant-garde, that autochthonous avantgarde magazines are more likely to mention avant-garde artists from outside the Western mainstream, while favoring other East-Central European avantgarde writers such as Lajos Kassák (Hungary), Karel Teige (Czechoslovakia) or Ljubomir Micić (Yugoslavia). This preliminary observation contradicts a series of clichés regarding the Western influence on the Romanian avant-garde, while simultaneously illustrating that Western avant-garde had an outstanding visibility in the Romanian cultural "mainstream".

These are only a few isolated instances where quantitative approaches to literature can challenge the existing critical consensus. What we have attempted to demonstrate above is the viability of the method and its use in a peripheral (non-centric) culture such as Romania. Even with the use of analog lexicographical instruments such as the dictionaries and bibliographies showcased above, it is evident that the methods popularized by scholars such as Franco Moretti (Moretti 2013), Matthew L. Jockers (Jockers 2013) or Katherine Bode (Bode 2014) show promise.

In lieu of more definitive concluding remarks, we should point out that there are a few promising research projects in full swing in the Romanian academic space that might be able to "upgrade" our existing quantitative and distant reading endeavors. One such project is Astra Data Mining. The Digital Museum of the Romanian Novel: The Nineteenth Century, coordinated by Ștefan Baghiu and Vlad Pojoga, that succeeded in digitizing the majority of Romanian $19^{\text {th }}$ century novels and is currently in the process of developing a methodology for corpus management using digital tools that will enable complex computational analyses on literary corpora. Another one is the Hai-Ro project, a French-Romanian collaboration whose aim is to use TEI encoding on a series of genre-specific 
Mapping Literature Through Quantitative Instruments

novels. Last but not least, the international COST action Distant Reading for European Literary History is a transnational experimental project that attempts to create a comprehensive European literary corpus using novels published between 1850 and 1920. These projects, alongside a series of articles published in the last decade (Goldiș 2014, Ursa 2015, Olaru 2019, Baghiu and Modoc 2019, Ciorogar and Modoc 2019, Pojoga et al 2019, Coroian-Goldiș et al 2019) represent the dawn of Digital Humanities in the field of Romanian literary studies.

\author{
Daiana Gârdan \\ alexandra.gardan@gmail.com \\ Universitatea Babeș-Bolyai \\ Facultatea de Litere \\ Str. Horea nr. 31 \\ 400202 Cluj-Napoca \\ ROMÂNIA / ROMANIA \\ Emanuel Modoc \\ ermodoc@gmail.com \\ Academia Română \\ Filiala Cluj-Napoca \\ Institutul de Lingvistică și Istorie Literară "Sextil Pușcariu” \\ Str. Emil Racoviță nr. 21 \\ 400165 Cluj-Napoca \\ ROMÂNIA / ROMANIA
}

\title{
References
}

Baghiu, Ș. 2016. Translating Novels in Romania: The Age of Socialist Realism. From an Ideological Center to its Geographical Margins. - Studia UBB Philologia, LXI (1), 5-18.

Baghiu, Ș. 2019a. Translating Hemispheres: Eastern Europe and the Global South Connection through Translationscapes of Poverty. - Comparative Literature Studies, 56 (3), 487-503. https://doi.org/10.5325/complitstudies.56.3.0487

Baghiu, S,. 2019b. The French Novel in Translation: A Distant Reading for Romania During Communism (1944-1989). - Transylvanian Review, XXVIII (1), 83-100.

Baghiu, S., Modoc, E. 2019. New Paradigms in Contemporary Romanian Literary Studies. - Transilvania, 5-6, 13-16.

Bâlici, M. 2018. The Emergence of Quantitative Studies. Actual Functionalities and the Romanian Case. - Metacritic Journal for Comparative Studies and Theory, 4 (2), 54-71. https://doi.org/10.24193/mjcst.2018.6.04

Bode, K. 2014. Reading by Numbers. London: Anthem Press. 
GÂRDAN, MODOC

Borza, C. 2019. How to Populate a Country. A Quantitative Analysis of the Rural Novel from Romania (1900-2000). - Ștefan Baghiu, Vlad Pojoga, Maria Sass, eds. Ruralism and Literature in Romania. Berlin: Peter Lang, 21-40.

Burța-Cernat, B. 2018. Gândirea critică și simulacrele ei (Critical Thinking and Its Simulacra). - Observator cultural, 911 (February).

Ciorogar, A., Modoc, E. 2019. Analiza computațională în cadrul studiilor literare românești (Computational Analysis and the Romanian Literary Studies). Observator cultural, 981 (August).

Coroian-Goldiș, A., Gârdan, D., Modoc, E., Susarenco, T., Morariu, D., Borza, C. 2019. Arhivele romanului românesc și posibilități de digitizare (The Archives of the Romanian Novels and Digitization Possibilities). - Transilvania, 10, 1-8.

Emirbayer, M. 1997. Manifesto for a Relational Sociology. - American Journal of Sociology, 103 (2), 281-317. https://doi.org/10.1086/231209

English, J. F. 2010. Everywhere and Nowhere: The Sociology of Literature after "the Sociology of Literature". - New Literary History, 41 (2), 5-23. https://doi. org/10.1353/nlh.2010.0005

Gârdan, D. 2018a. Evoluția romanului erotic românesc din prima jumătate a secolului al XX-lea. Între exercițiu și canonizare (The Evolution of the Romanian Erotic Novel from the First Half of the $20^{\text {th }}$ Century. Between Exercise and Canonization). - Transilvania, 7, 5-10.

Gârdan, D. 2018b. The Great Female Unread. Romanian Women Novelists in the First Half of the Twentieth Century: A Quantitative Approach. Metacritic Journal for Comparative Studies and Theory, 4 (1), 109-124. https://doi.org/10.24193/ mjcst.2018.5.07

Goldiș, A. 2014. Digital Humanities - o nouă paradigmă teoretică? (Digital Humanities - A New Theoretical Paradigm?). - Transilvania, 12, 1-4.

Jockers, M. L. 2013. Macroanalysis. Digital Methods \& Literary History. Urbana: University of Illinois Press.

Mansbach, S.A. 1999. Modern Art in Eastern Europe: From the Baltic to the Balkans, 1890-1939. Cambridge: Cambridge University Press.

Martin, M., Moraru, Ch., Terian, A., eds. 2018. Romanian Literature as World Literature. New York: Bloosmbury.

Modoc, E. 2018. Travelling Avant-Gardes. The Case of Futurism in Romania. - Maria Sass, Ștefan Baghiu, Vlad Pojoga, eds., The Culture of Translation in Romania. Berlin: Peter Lang, 45-61.

Moretti, F. 2013. Distant Reading. London: Verso.

Olaru, O. 2019. What is Digital Humanities and What's It Doing in Romanian Departments? - Transilvania, 5-6, 30-37.

Patraș, R. Galleron, I. Grădinaru, C. Lionte, I, Pascaru, L. 2019. The Splendors and Mist(eries) of Romanian Digital Literary Studies: A State-of-the-Art just before Horizons 2020 Closes Off. - Hermeneia, 23, 207-222.

Pojoga, V., Baghiu, Ș., Modoc, E., Gârdan, D., Coroian-Goldiș, A. 2019. Tehnici digitale pentru analiza romanului românesc (Digital Tools for the Analysis of the Romanian Novel). - Transilvania, 10, 9-16. 
Mapping Literature Through Quantitative Instruments

Ramsdell, K. 1999. Romance Fiction: A Guide to the Genre. Englewood, Colorado: Liraries Unlimited, Inc.

Tennen, D. 2017. Visual-Quantitative Approaches to the Intellectual History of the Field. A Close Reading. - Ursula K. Heise, ed., Futures of Comparative Literature, ACLA State of the Discipline Report. London; New York: Routledge, 258-266. https://doi.org/10.4324/9781315227405-45

Terian, A. 2019. Big Numbers: A Quantitative Analysis of the Development of the Novel in Romania. - Transylvanian Review, XXVIII (1), 55-71.

Ursa, M. 2015. Is Romanian Culture Ready for the Digital Turn? - Metacritic Journal for Comparative Studies and Theory, 1 (1), 80-97.

WReC: Warwich Research Collective 2015. Combined and Uneven Development: Towards a New Theory of World Literature. Liverpool: Liverpool University Press. 